\title{
Puccinia hemerocallidis, Cause of Daylily Rust, a Newly Introduced Disease in the Americas
}

\author{
José R. Hernández, USDA, Agricultural Research Service, Systematic Botany and Mycology Laboratory (ARS, \\ SBML), Beltsville, MD 20705-2350; Mary E. Palm, USDA, Animal and Plant Health Inspection Service (APHIS), \\ SBML, Beltsville, MD 20705-2350; and Lisa A. Castlebury, USDA, ARS, SBML, Beltsville, MD 20705-2350
}

\begin{abstract}
Hernández, J. R., Palm, M. E., and Castlebury, L. A. 2002. Puccinia hemerocallidis, cause of daylily rust, a newly introduced disease in the Americas. Plant Dis. 86:1194-1198.

A rust of daylilies was introduced recently into North and Central America. In order to confirm the identity of this rust as Puccinia hemerocallidis, numerous specimens from Costa Rica and the United States were examined morphologically and compared with specimens from China, Japan, Russia, and Taiwan. In addition, the internal transcribed spacer (ITS) region of the ribosomal DNA was sequenced from six representative fresh specimens from the Americas and Asia. We conclude that the rust introduced into the Americas is $P$. hemerocallidis, for which a modern description is provided with illustrations of the uredinial and telial stages.
\end{abstract}

Daylilies (Hemerocallis spp., Liliaceae) are one of the most important cultivated perennial plants in the United States. Daylily rust, a serious disease caused by Puccinia hemerocallidis Thüm., was observed in Georgia in August 2000 (14) and was found in at least 20 other states and in Costa Rica in 2001. It was originally described from Russia, reported throughout the Japanese archipelago, and recorded from China (Manchuria), Korea, and Taiwan $(4,5)$.

Among the rust fungi, only $P$. hemerocallidis is known to infect Hemerocallis spp. This study was undertaken because initial observations of variation in urediniospore morphology and the presence of many nonseptate teliospores (mesospores) in the rust in the Americas suggested that it might be different from the Asian rust and that there might even be heterogeneity within the American rust. The type specimen of $P$. hemerocallidis from Siberia, Russia, was examined and compared with both recently and previously collected specimens from China, Costa Rica, Japan, Russia, Taiwan, and the United States. This report provides an expanded description with photomicrographs of the fungus causing daylily rust.

Corresponding author: J. R. Hernández

E-mail: jose@nt.ars-grin.gov

Accepted for publication 10 June 2002.

Publication no. D-2002-0903-01R

This article is in the public domain and not copyrightable. It may be freely reprinted with customary crediting of the source. The American Phytopathological Society, 2002.
Additionally, the internal transcribed spacer (ITS) region of the ribosomal DNA was sequenced for specimens from Costa Rica, Japan, Russia, and the United States to compare the rust fungus from the Americas with recently collected Asian specimens of $P$. hemerocallidis.

\section{MATERIALS AND METHODS}

Herbarium specimens from the U.S. National Fungus Collections (BPI), Arthur Herbarium (PUR), and Herbarium of Systematic Mycology, Ibaraki University, Japan, were examined. In addition, fresh specimens were obtained from colleagues in Russia and Japan, and from the United States and Costa Rica through USDA, APHIS interceptions and state surveys conducted in 2001 (see specimens examined). These collections were deposited at BPI.

Morphology. Forty-two specimens were examined. For microscopic studies, spores were placed in a drop of Shear's mounting medium $(50 \%$ potassium acetate [ $2 \%$ aq.], $20 \%$ glycerine, $30 \%$ ethyl alcohol [95\%]) and measured. Microscopic observations were made using a Zeiss Axioplan 2 compound microscope, and spores were measured using Scion Image software. SYSTAT 10 (SPSS Science, Chicago, IL) was used to statistically analyze spore measurements. The size range is given followed by the mean, standard deviation of error, and number of measurements taken (n). Scatterplots for urediniospore and teliospore dimensions were constructed using SYSTAT 10. The Gaussian bivariate ellipses are graphed for the samples in each plot. The resulting ellipses are centered on the sample measurements of the $x$ and $y$ vari- ables. The unbiased sample standard deviations of $x$ and $y$ determined their major axes, and the orientation is determined by the sample covariance between $x$ and $y$. A probability of 0.683 was used to determine the size of the ellipses. Urediniospores were placed in a drop of $0.1 \%$ cotton blue/lactic acid to observe germ pores. Photomicrographs of fungal structures were taken using a Nikon DXM1200 digital camera.

Molecular analysis. Genomic DNA was extracted from crushed teliospores or urediniospores as described by Taylor and Swann (9). Ribosomal ITS 1 and 2, including the 5.8S ribosomal DNA (rDNA), were amplified for the following specimens: BPI 841401 (Japan), BPI 840988 (Russia), BPI 748483 (Costa Rica), BPI 749105 (Costa Rica), BPI 746996 (United States), and BPI 841369 (United States). Reactions (50 $\mu \mathrm{l})$ were run on a GeneAmp 9700 thermal cycler (Applied Biosystems, Foster City, CA) under the following reaction conditions: approximately $1 \mathrm{ng}$ of genomic DNA, $200 \mathrm{mM}$ each dNTP, 2.5 units AmpliTaq Gold (Applied Biosystems), 25 pmoles each of primers ITS5 and ITS4b $(3,10,13)$, and the supplied $10 \times$ polymerase chain reaction (PCR) buffer with $15 \mathrm{mM}$ $\mathrm{MgCl}_{2}$. The thermal cycler program was as follows: $10 \mathrm{~min}$ at $95^{\circ} \mathrm{C}$ followed by 40 cycles of $30 \mathrm{~s}$ at $94^{\circ} \mathrm{C}, 30 \mathrm{~s}$ at $55^{\circ} \mathrm{C}$, and 1 min at $72^{\circ} \mathrm{C}$, with a final extension period of $10 \mathrm{~min}$ at $72^{\circ} \mathrm{C}$. After amplification, the PCR products were purified with QIAquick columns (Qiagen Inc., Chatsworth, CA) according to the manufacturer's instructions. Amplified products were sequenced in each direction with the BigDye version 2.0 kit (Applied Biosystems) on an ABI 310 automated DNA sequencer.

PCR products that could not be sequenced directly were cloned using the TOPO TA Cloning kit (Invitrogen Corporation, Carlsbad, CA). Plasmids were purified with the Perfectprep Plasmid Mini kit (Eppendorf, Hamburg, Germany). Two clones per specimen were sequenced in each direction with the ITS5 and ITS4b primers used for the PCR and compared with the sequences of the directly sequenced PCR products. The resulting sequences were edited and aligned using 
Sequencer version 4.05 for Windows (Gene Codes Corporation, Ann Arbor, MI) and deposited in GenBank as accession numbers AF479739 to AF479744.

\section{RESULTS}

Morphology. The range of variability of certain morphological characteristics found in this study is greater than indicated in the literature $(4,5,12)$. Telia in collections from the Americas were smaller, less dense, and had many nonseptate teliospores compared with those in the Asian collections in which telia were dense and with mostly 1 septate teliospores. The ratio of nonseptate to 1-septate teliospores was variable between different sori within one specimen and among specimens. Some of the teliospores in the recent Japanese collections were found to be 2-septate and longer than those in the specimens from the Americas and Russia. Both teliospore and urediniospore sizes varied among specimens from different geographical regions, but the ellipses formed in scatterplots overlapped (Fig. 1). Hiratsuka et al. (5) mentioned brown paraphyses in the telia of $P$. hemerocallidis, but no paraphyses were observed in any of the specimens examined.

The following description of $P$. hemerocallidis is based on examination of numerous specimens and expands the known morphological variation of this species on daylily.

Puccinia hemerocallidis Thüm., Bull. Soc. Imp. Nat. Moscow 55:81. 1880. (Fig. 2A to $\mathrm{H}$ )

Uredinia are first evident as hypophyllous, small, dark, circular to irregularly shaped, interveinal lesions that are initially less than $1 \mathrm{~mm}$ in diameter and $2 \mathrm{~mm}$ or more at maturity. A corresponding chlorotic area can be seen on the adaxial leaf surface. Uredinia are subepidermal, becoming erumpent, and often have a narrow, dark margin. The broken epidermis surrounds the mature uredinial sori, which are round to elongate and pale yellowish to yellow to orangish yellow. On older or otherwise chlorotic leaves, the yellow sori often are surrounded by a green halo. When the leaves are heavily infected, the sori often become confluent and the lower leaf surface appears bright yellow due to the numerous urediniospores.

Urediniospores are yellow, globose to ellipsoid, (13.5-) 21-26.5 (-36) $\times(12-)$ 18.5-22.5 (-29.5) $\mu \mathrm{m}$ (mean $=24 \mu \mathrm{m} \pm 2.8$ by $20.5 \mu \mathrm{m} \pm 2.2, \mathrm{n}=1,041)$. The urediniospore wall is hyaline, echinulate, variable in width, measuring 1 to $2.5 \mu \mathrm{m}$ when young and 2 to $3.5(-4)$ (mean $=2.6 \mu \mathrm{m} \pm$ $0.6, \mathrm{n}=128) \mu \mathrm{m}$ at maturity, with five to six obscure germ pores observable with cotton blue. Urediniospores are subtended by a nonpersistent pedicel that is infrequently attached to the spore. No paraphyses were observed.

Telia are primarily hypophyllous, subepidermal, and either remain covered by the epidermis, as in most Asian specimens, or erumpent, as in some U.S. specimens. Telia are round to slightly elongate and 0.5 to $1.5 \mathrm{~mm}$ in diameter. In American specimens, telia appear brownish and less dense compared with the telia in Asian specimens, which are blackish brown, dense, and compacted. No paraphyses were observed.

Teliospores are variable but mostly ellipsoidal to clavate with an apical papilla, or angular with an eccentric papilla. Teliospores are nonseptate to 1-septate, rarely 2septate, and usually slightly constricted at the septa. Nonseptate teliospores measure (21.5-) 27.5-38.5 (-46.5) × (10-) 13-16.5 $(-19.5) \mu \mathrm{m}($ mean $=33 \mu \mathrm{m} \pm 5.3$ by 14.6 $\mu \mathrm{m} \pm 1.9, \mathrm{n}=95)$, and 1-septate teliospores are (28.5-) 36-51.5 (-66.5) × (10.5-) 14.5$19(-22.5) \mu \mathrm{m}$ (mean $43.9 \mu \mathrm{m} \pm 7.7$ by 16.6 $\mu \mathrm{m} \pm 2.3, \mathrm{n}=233)$. The teliospore wall is smooth, brownish, darker brown at the apex, 1 to $1.5 \mu \mathrm{m}$ at sides, and (1.5-) 3-8 $(-10.0) \mu \mathrm{m}($ mean $=5.6 \mu \mathrm{m} \pm 2.5, \mathrm{n}=34)$ at apex. In each probasidial cell, there is one germ pore near the apex in the upper cell and one germ pore adjacent to the septum in the lower cell.

Specimens examined:

CHINA: Kushan, Foochow, on Hemerocallis sp., 14 August 1933, S.C. Teng s.n. (BPI 72681) [II-III]; Shennongjia, Hubei Prov., 10 August 1984, Lin Guo s.n. (BPI 199085) [II-III].

COSTA RICA: on Hemerocallis sp., intercepted in Miami, FL, 17 March 2001, T.T. Dobbs s.n. (BPI 748483) [II], sequenced (AF479740); on Hemerocallis sp. cv. Little Dandy, intercepted in Miami, FL, 17 March 2001, W.J. Pagan s.n. (BPI 749105) [II], sequenced (AF479741).

JAPAN: Gumma, Tano-gun, on Hemerocallis fulva L. var. longituba (Miq.) Maxim., 20 October 2001, Y. Ono 4772 (BPI 841401) [II-III], sequenced (AF479743); Morioka, Iwate Prefecture, on Hemerocallis fulva L. var. kwanso, 24 September 1926, K. Togashi s.n. (BPI 072721) [II-III]; Oze-Ga-Hara, Iwashiro Prov., on Hemerocallis middenforfii, 6 September 1950, N. Hiratsuka s.n. (BPI 72722) [II-III]; Ryukyu Islands, on Hemerocallis disticha, 29 May 1953, N. Hiratsuka \& S. Shimabukuro s.n. (BPI 72697) [II]; Tochigi, Aso-gun, on Hemerocallis fulva var. longituba, 20 October 2001, Y. Ono 4776 (BPI 841403) [II-III].

RUSSIA: Primorsky Territory, on Hemerocallis esculenta Koidz., 23 September 2001, L. Vasilyeva s.n. (BPI 841399) [II-III]; on Hemerocallis minor Mill., 23 September 2001, L. Vasilyeva s.n. (BPI 841404) [II-III]; on Hemerocallis sp., 9 August 2001, L. Vasilyeva s.n. (BPI 840988) [II], sequenced (AF479744); Western Siberia, on Hemerocallis flava (L.) L., 1878, $N$ Martianoff s.n. (BPI 072719 - isotype) [III].

TAIWAN: Prov. Taihoku, on Hemerocallis sp., 24 February 1929, K. Sawada s.n. (BPI 72684) [II].
UNITED STATES:

Alabama: Limestone Co., on Hemerocallis sp., 4 September 2001, L. Chapman s.n. (BPI 841406) [II].

California: Los Angeles Co., on Hemerocallis sp., 2 April 2001, Burton s.n. (BPI 746996) [II], sequenced (AF479739); Orange Co., on Hemerocallis sp. cv. Tiger Time, 26 March 2001, M. Luque-Williams s.n. (BPI 841369) [II], sequenced (AF479742); San Diego Co., on Hemerocallis sp., 14 January 2002, P. Nolan s.n. (BPI 841670) [II-III].

Connecticut: New Haven Co., on Hemerocallis sp. cv. Lake Effect, 13 July 2001, R. Howard s.n. (BPI 841429) [II].

Florida: St. Johns Co., on Hemerocallis sp., 22 March 2001, Richards s.n. (BPI 841409) [II-III].

Georgia: Athens, on Hemerocallis sp. cv. Pardon Me, 29 November 2000, J. Williams-Woodward s.n. (BPI 841432) [II]; on P. hemerocallidis cv. Star Struck, 29 November 2000, J. Williams-Woodward s.n. (BPI 841436) [II].

Hawaii: Kurtistown, on Hemerocallis sp. cv. Ruby Sullivan, 5 February 2002, B.C. Bushe s.n. (BPI 841765) [II-III].

Illinois: Saline Co., on Hemerocallis sp., 3 August 2001, A. Cluck s.n. (PUR N1546, BPI 840986) [II].

Indiana: Floyd Co., on Hemerocallis sp., 24 July 2001, D.E. Crooks s.n. (PUR
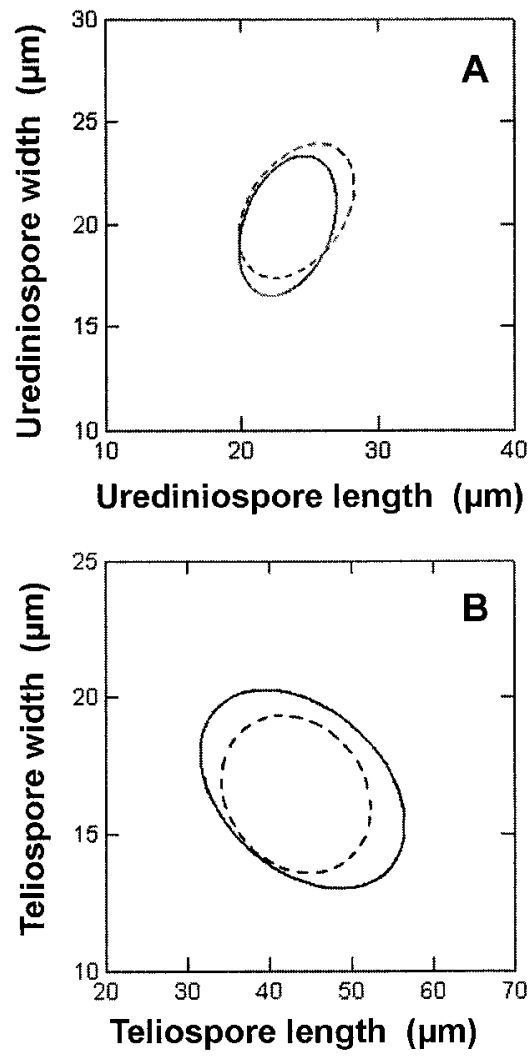

Fig. 1. Ellipses calculated from scatterplot of width and length of American (broken line) and Asian (solid line) A, urediniospores, and $\mathbf{B}$, teliospores. 
N1322, BPI 840984) [II].

Kentucky: Lexington, on Hemerocallis sp., 16 July 2001, J. Beale \& J. Hartman s.n. (BPI 841410) [II].

Louisiana: Iberia Parish, on Hemerocallis sp., 11 April 2001, J. Dunkley \& K. Champagne s.n. (BPI 841412) [II-III]; Lincoln Parish, on Hemerocallis sp. cv. Golden Compass, 14 September 2001, J. Dunkley s.n. (BPI 841427) [II].

Maryland: Howard Co., on Hemerocallis sp. cv. Dominic, 27 June 2001, A.B. Sindermann s.n. (BPI 841420) [II].

Missouri: Gasconade Co., on Hemerocallis sp. cv. Elizabeth's Magic, 17 July 2001, K. Vitoux s.n. (BPI 841422) [II]; Boone Co., on Hemerocallis sp. cv. Lavendar, 31 July 2001, L. Kabrick s.n. (BPI 841430) [II].

New Jersey: Monmouth Co., on Hemerocallis sp., 11 September 2001, M. Lovasz s.n. (BPI 841413) [II].

New York: Suffolk Co., on Hemerocallis sp. cv. Dan Mahony, 14 August 2001, M. Daughtrey s.n. (BPI 841418) [II]; on Hemerocallis sp. cv. Darla Anita, 14 August 2001, M. Daughtrey s.n. (BPI 841419) [II].

North Carolina: Buncombe Co., on Hemerocallis sp. cv. Autumn Jewels, 20
August 2001, T. Creswell s.n. (BPI 841415) [II]; Henderson Co., on Hemerocallis sp., 6 August 2001, T. Creswell s.n. (BPI 841414) [II]; Rutherford Co., on Hemerocallis sp. cv. Dream Shadows, 6 September 2001, J.F. Kennedy s.n. (BPI 841421) [II].

South Carolina: Clemson, on Hemerocallis sp. cv. Colonel Scarborough, 7 December 2000, K. Glenn s.n. (BPI 841416) [II-III]; on Hemerocallis sp. cv. Crystal Tide, 7 December 2000, K. Glenn s.n. (BPI 841417) [II-III].

Tennessee: Lawrence Co., on Hemerocallis sp., 21 June 2001, C. Bilbrey s.n. (BPI 746997) [II]; Davidson Co., on Hemerocallis sp. cv. Elizabeth's Magic, 6 June 2001, C. Bilbrey s.n. (BPI 841423) [II].

Wisconsin: Iowa Co., on Hemerocallis sp. cv. Enchanting Esmeralda, 24 July 2001, A. Mengistu s.n. (BPI 841425) [II].

Molecular analysis. The ITS sequences differed at 10 positions across the approximately $600 \mathrm{bp}(<2 \%$ sequence divergence) sequenced for each of the six specimens (Fig. 3). The two Asian specimens shared two base substitutions and one insertion/deletion (indel) that did not occur in the American specimens. In addition, one position that was ambiguous in two of the American specimens (adenine or thymine) and thymine in the other two American specimens was adenine in the Asian specimens. The two Asian specimens differed from one another at four positions: one substitution (cytosine to thymine), two indels, and one ambiguity in the Japanese specimen cytosine or thymine versus an unambiguous thymine in the Russian specimen (Fig. 3).

The four American specimens differed in three positions. Two specimens shared an ambiguity (adenine or thymine), while the other two were clearly thymine in one position, and the remaining two positions were indels in a poly-thymine (poly-T) region that ranged from 9 to 11 residues in these sequences (Fig. 3). The American specimens were difficult to sequence directly from PCR products because of a poly-T region in the ITS 1 that apparently caused the Taq polymerase to slip during the extension step, resulting in a population of PCR products differing from one another in length by 1 bp. Resulting sequences were unreadable after the poly- $T$ region, which necessitated cloning the
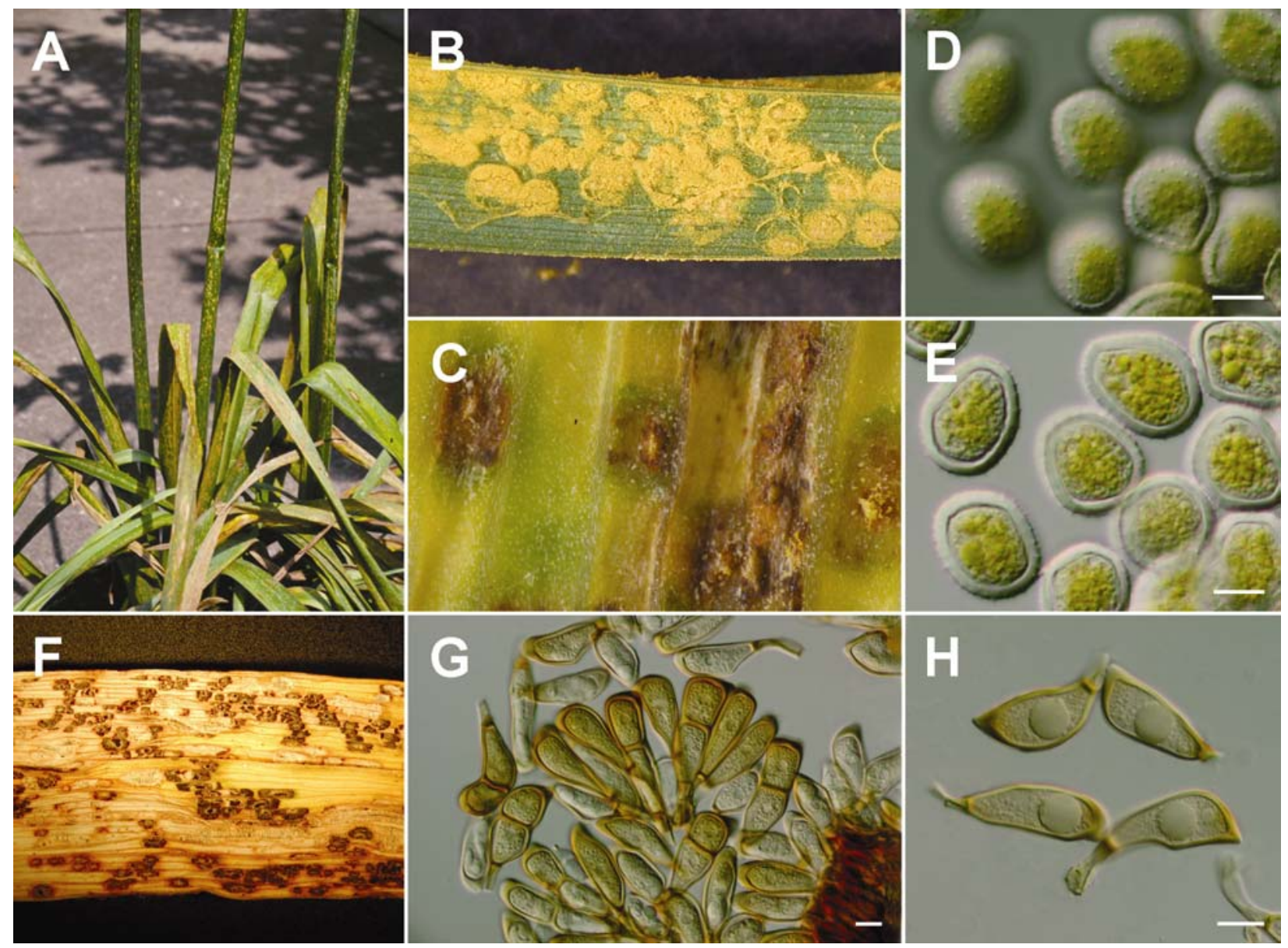

Fig. 2. Daylily rust caused by Puccinia hemerocallidis. A, Heavily infected potted daylily plant with uredinia (courtesy of T. Schubert). B, Mature uredinial sori with numerous yellow urediniospores on abaxial leaf surface (BPI 841432). C, Chlorotic leaf with few yellowish-brown, erumpent uredinia surrounded by a green halo (courtesy of T. Schubert). D, Surface view of echinulate urediniospores (BPI 841416). E, Median view of urediniospores in D. F, Dark, erumpent telia on chlorotic and necrotic leaf (BPI 841670). G, Mesospores and 1-septate teliospores (BPI 841416). H, Mesospores, common in American collections (from BPI 841417). Bar $=10 \mu \mathrm{m}$. 
products to ensure that a single amplification product was sequenced. Cloned fragments produced clean sequences following the poly-T region, suggesting that it was a problem in the PCR and not a sequencing chemistry issue.

Although a DNA polymerase with proofreading abilities (Pwo polymerase, Roche Molecular Biochemicals, Indianapolis, IN) was used in an attempt to resolve this problem, it did not produce ITS products of a single length that could be sequenced directly and read unambiguously. Differences in sequence lengths were found among different clones from the same PCR amplification, due to the differing number of thymine residues. The two indels in this poly- $T$ region from the American specimens mentioned previously are mostly likely artifacts of the polymerase "slippage" and not real differences. In the Asian specimens, the poly-T region was broken by a single adenine, and the PCR products could be sequenced directly. Sequences deposited in GenBank represent the minimum number of thymine residues found for each specimen. Virtudazo et al. (10) also reported a similar problem in sequencing the ITS region from sugarcane rusts.

A BLAST search of GenBank (1) with the ITS sequence of the Russian specimen found sequences of Uromyces pisi (Pers.) Wint. from Euphorbia cyparissias L. (AF180169, AF180170, AF180176 to AF180180, AF180184) and U. striatus Schröt. from Trifolium arvense $\mathrm{L}$. (AF180160 to AF180162) to be the best matches of the rust sequences available in the database. However, none of the sequences available in GenBank could be aligned with the $P$. hemerocallidis sequences well enough to investigate the relationship of $P$. hemerocallidis to other rust species in the database.

\section{DISCUSSION}

The ITS region has been used to determine identities and phylogenetic relation- ships with other rust species $(3,10,11)$, as well as many other fungi, and is easily amplifiable with rust-specific primers even in the presence of host DNA (3). Virtually all available sequences in GenBank for rust fungi are for the ITS region. For the six specimens sequenced, ITS variation within the American specimens or within the Asian specimens was approximately equal to variation between specimens from the two broad geographic areas and indicates that the specimens are the same species. Two fixed substitutions and one insertion/deletion were present in the ITS regions that distinguished the two Asian specimens from the four American specimens. However, because of the limited sampling and the absence of significant morphological differences between specimens from the two broad geographic areas, no conclusions about the significance of these substitutions can be made.

$P$. hemerocallidis has been reported from Austria (7); however, after examining the specimen (Austria, Niederoesterreich, Tulln, Baumschule Gebhard \& Fussel, on Hemerocallis sp; 23 July 1984, R. Fischer s.n. PUR N1738 [II]), we conclude that the fungus and host were misidentified. The urediniospores of the Austrian rust have three to four prominent, more or less equatorial germ pores with hyaline caps, whereas those of $P$. hemerocallidis have five to six obscure, scattered germ pores with no caps. Urediniospores of the Austrian specimen had more dense and evenly distributed echinulations than those of $P$. hemerocallidis. Additionally, the urediniospores of the former were found to be significantly larger than those of $P$. hemerocallidis (mean $=29 \mu \mathrm{m} \pm 3.2$ by $21 \mu \mathrm{m} \pm 2.2, \mathrm{n}=21$; cell wall $2.1 \mu \mathrm{m}$ $\pm 0.5, \mathrm{n}=14)$. No telia were observed in the Austrian collection. The morphology of the leaf was inconsistent with that of species of Hemerocallis (C. Feuillet, personal communication). Therefore, the report of $P$. hemerocallidis in Europe is erroneous.
The center of origin of the daylily (Hemerocallis spp.) is eastern Asia (6). P. hemerocallidis was described from Russia (Siberia) (12) and, until 2000, known only from eastern Asia. Rusts are obligate parasites that usually coevolve with their host (8), and therefore Asia is likely the center of origin of $P$. hemerocallidis. P. hemerocallidis is reported to be heteroecious, producing the spermagonial and aecial stages on Patrinia (Valerianaceae), also native to Asia (2). To date, no rust infections have been reported on Patrinia in the United States, where, although that host is neither native nor common, it is becoming more popular as a cultivated plant.

At present, $P$. hemerocallidis is reported from eastern Asia and many states in the United States as well as from Costa Rica. The disease first was observed in Georgia in the summer of 2000 (14). Although there are reports from Florida that the rust had been present in that state for several years, no voucher specimens are available for confirmation. In past years, daylilies have been shipped from the United States to Costa Rica and other Central American countries to be multiplied during the North American winter. Trimmed cuttings are subsequently shipped back to several southeastern states, where they are sold throughout the United States and to other countries. Additionally, daylilies are grown and traded extensively by hobbyists.

All evidence suggests that $P$. hemerocallidis inadvertently was introduced into the Americas quite recently, although where it was first introduced is uncertain. The widespread movement of daylilies in commerce and among enthusiasts contributed to the rapid spread of this rust in the continental United States and recently to Hawaii. General information about daylily rust, including control measures, can be found at the USDA APHIS website.

\section{ACKNOWLEDGMENTS}

We thank Yoshitaka Ono and Larissa Vassilyeva for sending specimens from Japan and Russia, respectively, and to Markus Scholler, Director of

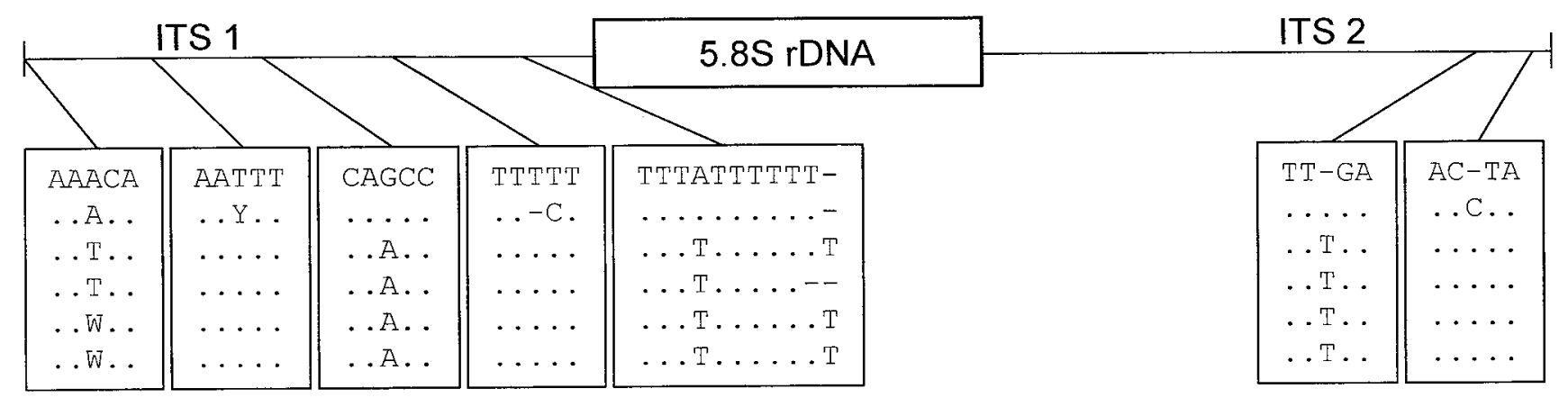

Poly-T region

Fig. 3. Internal transcribed spacer (ITS) sequence differences among specimens of Puccinia hemerocallidis. Order of sequences is as follows from top to bottom: BPI 840988 (Russia), BPI 841401 (Japan), BPI 746996 (United States), BPI 841369 (United States), BPI 748483 (Costa Rica), BPI 749105 (Costa Rica). Only regions where differences occurred are shown. All other positions were identical. Dashes represent alignment gaps, and periods indicate the position was identical to the first sequence. Figure is not drawn to scale, although relative positions of the differing regions are shown. The poly-T region that caused sequencing difficulties in the specimens from the Americas is indicated on the figure. 
the Arthur Herbarium (PUR) for the loan of the Austrian collection. We express our appreciation to Amy Rossman for facilitating and supporting this work and to Douglas Linn for sequencing some of the isolates for this study. Thanks are extended to Tim Schubert, Florida Department of Plant Industry, for several of the photographs.

\section{LITERATURE CITED}

1. Altschul, S. F., Gish, W., Miller, W., Myers, E. W., and Lipman, D. J. 1990. Basic local alignment search tool. J. Mol. Biol. 215:403410 .

2. Bailey, L. H., and Bailey, E. Z. 1976. Hortus Third. A Concise Dictionary of Plants Cultivated in the United States and Canada. Macmillan Publishing Co., New York.

3. Gardes, M., and Bruns, T. D. 1993. ITS primers with enhanced specificity for basidiomycetes - application to the identification of mycorrhizae and rusts. Mol. Ecol. 2:113-118.

4. Hiratsuka, N., and Hasebe, S. 1978. A taxonomic revision of the species of Puccinia parasitic on the Liliales (Liliaceae, Amarylli- daceae, Dioscoreaceae and Iridaceae) in the Japanese Archipelago. Rep. Tott. Mycol. Inst. 16:1-36.

5. Hiratsuka, N., Sato, S., Katsuya, K., Kakishima, M., Hiratsuka, Y., Kaneko, S., Ono, Y., Sato, T., Harada, Y., Hiratsuka, T., and Nakayama, K. 1992. The Rust Flora of Japan. Tsukuba Shuppankai, Takezono, Ibaraki, Japan.

6. Jelitto, L., and Schacht, W. 1995. Hardy Herbaceous Perennials. Vol. I. Timber Press, Portland, OR.

7. Poelt, J. 1985. Catalogus Florae Austriae. Thallophyten (Algen un Pilze), Uredinales. Verlag der •sterreichischen Akademie Wissenschaften.

8. Savile, D. B. O. 1990. Coevolution of Uredinales and Ustilaginales with vascular plants. Rep. Tott. Mycol. Inst. 28:15-24.

9. Taylor, J. W., and Swann, E. C. 1994. DNA from herbarium specimens. Pages 166-181 in: Ancient DNA: Recovery and Analysis of Genetic Material from Paleontological, Archaeological, Museum, Medical and Forensic Specimens. B. Herrmann and S. Hummel, eds.
Springer-Verlag, New York

10. Virtudazo, E. V., Nakamura, H., and Kakashima, M. 2001. Phylogenetic analysis of sugarcane rusts based on sequences of ITS, 5.8S rDNA and D1/D2 regions of LSU rDNA. J. Gen. Plant Pathol. 67:28-36.

11. Vogler, D. R., and Bruns, T. D. 1998. Phylogenetic relationships among the pine stem rust fungi (Cronartium and Peridermium spp.). Mycologia 90:244-257.

12. von Thümen, F. 1880. Beiträge zur Pilz-Flora Sibiriens. Bull. Soc. Natural. Moscou 55:72104.

13. White, T. J., Bruns, T., Lee, S., and Taylor, J. 1990. Amplification and direct sequencing of fungal ribosomal RNA genes for phylogenetics. Pages 315-322 in: PCR Protocols: A Guide to Methods and Applications. M. A. Innis, D. H. Gelfand, S. S. Sninsky, and T. J. White, eds. Academic Press, San Diego, CA.

14. Williams-Woodward, J. L., Hennen, J. F. Parda, K. W., and Fowler, J. M. 2001. First report of daylily rust in the United States. Plant Dis. 85:1121. 